(C) Practical Action Publishing, 2013. The definitive, peer-reviewed and edited version of this article is published in Waterlines, volume 32, number 4, pp 315-333. 2013, http://dx.doi.org/10.3362/1756-3488.2013.033.

\title{
A framework for exploring gender equality outcomes from WASH programmes
}

\author{
Naomi Carrard, Joanne Crawford, Gabrielle Halcrow, Claire Rowland and Juliet Willetts
}

Keywords: gender equality, gender outcomes, water, sanitation, hygiene

\section{Abstract}

This paper aims to assist practitioners and researchers in planning, identifying and documenting gender outcomes associated with water, sanitation and hygiene (WASH) programs by proposing a conceptual framework for classifying gender equality changes. Gender outcomes that have been attributed to WASH initiatives encompass those directly related to improved services as well as outcomes that move into areas of relationships, power and status. There is a growing body of literature identifying WASH-related gender outcomes, however the types of outcomes described vary considerably and further work is needed to inform a comprehensive picture of WASH and gender links. The framework proposed in this paper is based on a synthesis of outcomes reported in WASH literature to date, empirical research in Fiji and Vanuatu, and insights from gender and development literature. It is hoped that the framework will support practitioners to engage with the inherent complexity of gender inquiry, contributing to sector knowledge about the potential for WASH initiatives to advance gender equality.

\section{Introduction: From WASH outcomes to gender equality outcomes}

It has been well-established that focusing on gender - and more specifically encouraging women's meaningful participation - enhances the effectiveness and sustainability of WASH initiatives (Fisher, 2010; Van Wijk-Sijbesma, 1998 cited in Ivens, 2008; O'Reilly, 2010). More recently, a body of literature is emerging that considers gender equality outcomes from WASH programs more broadly. At the heart of this is acknowledgement of the fact that all development programs whether intentionally focused on gender or not, have different outcomes for women, men and relationships (Kilsby, 2012). The trend also reflects a broader shift in the WASH sector from a focus on technical dimensions towards social engagement strategies, and the centrality of socio-institutional frameworks in determining the likely sustainability of service provision (Lockwood and Smits, 2011). In the area of WASH, gendered outcomes can be particularly far reaching and wide ranging, given women's traditional roles in water, sanitation and hygiene management (Willetts et al. 2012).

From this recognition, the challenge for the WASH sector is to develop approaches that increase opportunities to facilitate positive, locally-determined gender equality outcomes, and avoid reinforcing or exacerbating existing inequalities. Recent research has examined how to direct practice to achieve positive gender equality outcomes, identifying themes and enablers in programs that have left a positive legacy (for example Fisher, 2010) and developing guidance materials to support practitioners engaging effectively with women and men in community WASH programs in the Pacific (Halcrow et al., 2010). 
To further this thinking there is a need for a synthesising framework for engaging with gender equality outcomes related to WASH so that policy makers, practitioners, development programmers and researchers can explore outcomes associated with WASH interventions in a more systematic and consistent way, and seek to ensure a focused, constructive and integrated approach to gender when designing and implementing future programs. As such, the aim of this paper is to propose an initial conceptual framework for locating and categorising the kinds of outcomes being reported, and those that can be plausibly anticipated given insights from gender and development literature.

\section{Approach}

The analysis and conceptual framework we propose was generated from a review of documented gender equality outcomes from WASH initiatives and empirical research undertaken in Fiji and Vanuatu. The review of documented outcomes involved collation of literature (including academic and grey literature) on WASH programs at various scales and in a range of locations. The focus was on reported outcomes and impacts associated with WASH programs, rather than simply the participation of women or a gender focus within program design and implementation, given that participation does not necessarily equate to gender equality changes, though this is often assumed to be the case (Ivens, 2008; O'Reilly, 2010). Inductive analysis was undertaken, identifying commonalities in both positive and negative outcomes reported as well as dimensions of difference. Literature on key concepts and frameworks for engaging with gender equality and women's empowerment in development were also consulted to identify critical areas of change (e.g. Moser, 1993; Kabeer, 1994; CARE, 2010; CARE, 2012; Golla et al., 2011; Hunt et al., 2009). From these, an initial conceptual framework was developed.

The review of reported outcomes drew on empirical research undertaken in Fiji and Vanuatu as part of a study of gender outcomes associated with WASH initiatives implemented by two nongovernment organisations (NGOs): Live and Learn Environmental Education in Fiji (Live \& Learn) and World Vision in Vanuatu. Outcomes relevant to the roles and relationships of men and women in each of the four case study communities were identified by participants in paired single-sex discussions, then shared and ranked in terms of importance to participants in separate groups of men and women. Women and men then together participated in a facilitated discussion exploring questions and issues arising from the process. The research approach used and outcomes reported are described fully in Willetts et al. (2010).

Bringing insights from the literature and empirical research together, the proposed conceptual framework was refined through a series of iterations. Secondary analysis of identified gender outcomes was undertaken to locate documented outcomes within the proposed framework, identifying common themes and associated generic 'outcome areas' for consideration in future WASH programs.

In the proposed framework, the term 'outcomes' includes both outcomes and impacts of WASH programs, as distinguishing between the two was not considered valuable for this review. Outcomes cover both direct results of programs (as reported), as well as changes that have occurred that are related to (but not necessarily solely caused by) the WASH initiative. This reflects the reality that changes in gender roles and responsibilities are socially and culturally mediated by a range of complex and interconnecting factors. It is impossible to isolate outcomes resulting from particular interventions from the context in which they occur, so we have not attempted to do so. Linking 
gender outcomes to WASH is nevertheless valid, given the significant body of evidence on the strong relationship between WASH and gender, and the reality that all development interventions including WASH programs have gendered outcomes.

\section{Towards a framework: What kinds of gender equality outcomes have WASH programs achieved to date?}

This section presents the proposed framework and, using the framework as a structure, provides a synthesis and review of a wide range of reported gender equality outcomes associated with WASH initiatives. Gender outcomes associated with WASH initiatives can be classified across two intersecting dimensions: (i) whether outcomes relate to individual changes or changes in relationships; and (ii) whether outcomes are experienced within the household sphere or in the wider 'public' arena. The public arena can be further broken down into the local realm (including social and community networks) and the broader public arena (including governance institutions and beyond). These dimensions intersect as shown in Figure 1.

Figure 1 Exploring gender equality through roles and relationships in private and public arenas

\begin{tabular}{|l|l|l|l|}
\hline \multirow{2}{*}{} & Household sphere & \multicolumn{2}{|c|}{ Public arena } \\
\cline { 2 - 4 } & $\begin{array}{l}\text { Household and family } \\
\text { networks }\end{array}$ & $\begin{array}{l}\text { Local public arena } \\
\text { Social and community } \\
\text { networks }\end{array}$ & $\begin{array}{l}\text { Broader public arena } \\
\text { Governance institutions and } \\
\text { beyond }\end{array}$ \\
\cline { 2 - 4 } $\begin{array}{l}\text { Changes in self/ individuals } \\
\begin{array}{l}\text { Includes changes for women } \\
\text { or men }\end{array}\end{array}$ & $\begin{array}{l}\text { Changes in roles, self- } \\
\text { perceptions and attitudes } \\
\text { within the household } \\
\text { sphere, related to family } \\
\text { roles as well as self- } \\
\text { perception and attitudes } \\
\text { networks and household } \\
\text { roles and responsibilities }\end{array}$ & $\begin{array}{l}\text { Changes in roles, self- } \\
\text { perceptions and attitudes } \\
\text { within the local public arena } \\
\text { including social networks, } \\
\text { community and local } \\
\text { institutions }\end{array}$ & $\begin{array}{l}\text { Changes in roles, self- } \\
\text { perceptions and attitudes } \\
\text { within the broader public } \\
\text { arena including national and } \\
\text { sub-national government } \\
\text { institutions, medium to } \\
\text { large scale private sector } \\
\text { actors }\end{array}$ \\
\hline $\begin{array}{l}\text { Changes in relationships } \\
\text { Includes changes in } \\
\text { relationships between } \\
\text { women/men and within } \\
\text { gender groups }\end{array}$ & $\begin{array}{l}\text { Changes in relationships } \\
\text { within the household } \\
\text { sphere, related to family } \\
\text { networks and household } \\
\text { roles and responsibilities }\end{array}$ & $\begin{array}{l}\text { Changes in relationships } \\
\text { within the local public arena } \\
\text { including social networks, } \\
\text { community and local } \\
\text { institutions }\end{array}$ & $\begin{array}{l}\text { Changes in relationships } \\
\text { within the broader public } \\
\text { arena including national and } \\
\text { sub-national government } \\
\text { institutions, medium to } \\
\text { large scale private sector } \\
\text { actors }\end{array}$ \\
\hline
\end{tabular}

This classification yields six distinct yet interconnected spaces in which gender equality outcomes can be situated. Personal and individual dimensions are part of any definition of the social dynamics that constitute gender equality, as what is possible at the individual level influences what is possible at other levels. The focus on individuals encompasses Moser's (1993) categorisation of women's various roles as reproductive, productive or relevant to community management, and also considers questions of self-perception and attitude which can play a catalytic role in gender equality and be outcomes in themselves. It also explicitly includes both women and men, reflecting the relevance of men's individual roles, perceptions and attitudes in the structures and social processes that shape gender equality (in addition to their critical place in relational processes). 
The focus on relationships reflects the social relations view of gender equality (after Kabeer 1994) in which social networks and relationships are seen to determine people's roles, rights, responsibilities and capacity to influence. It provides a lens for exploring power and status, as defined by position and relations within social networks across various institutions including families, communities, states and markets. Engaging with relationships is critical for any inquiry into gender equality as it is through relationships that the critical dynamics of power and status are defined. However, these issues are often overlooked. As O'Reilly (2010) asserts:

\section{Gender is understood as 'women' and 'men', instead of as the power relations between women and men that create them as distinct separate categories. Analysis of gender as a relational system is needed if women's participation in water supply and sanitation is to lead to their empowerment and effective sanitation.}

Across the horizontal axis, the framework is structured according to loosely defined scales of household, local public arena and broader public arena. The concept of scale as a way of framing conceptions of reality has been much discussed in human geography literature (e.g. Marston, 2000; 2001; Brenner, 2001), which takes a social constructionist view that processes at different scales both reflect and shape social relations. Scale therefore provides a helpful conceptual frame for investigating dynamics of gender equality (and has been used as such in selected gender analysis frameworks as discussed below), recognising that scales are nested, interconnected and overlapping. As such, the framework can also be conceived as a series of nested scales, within and across which individuals act and interact to shape gender roles and relationships as illustrated in Figure 2.

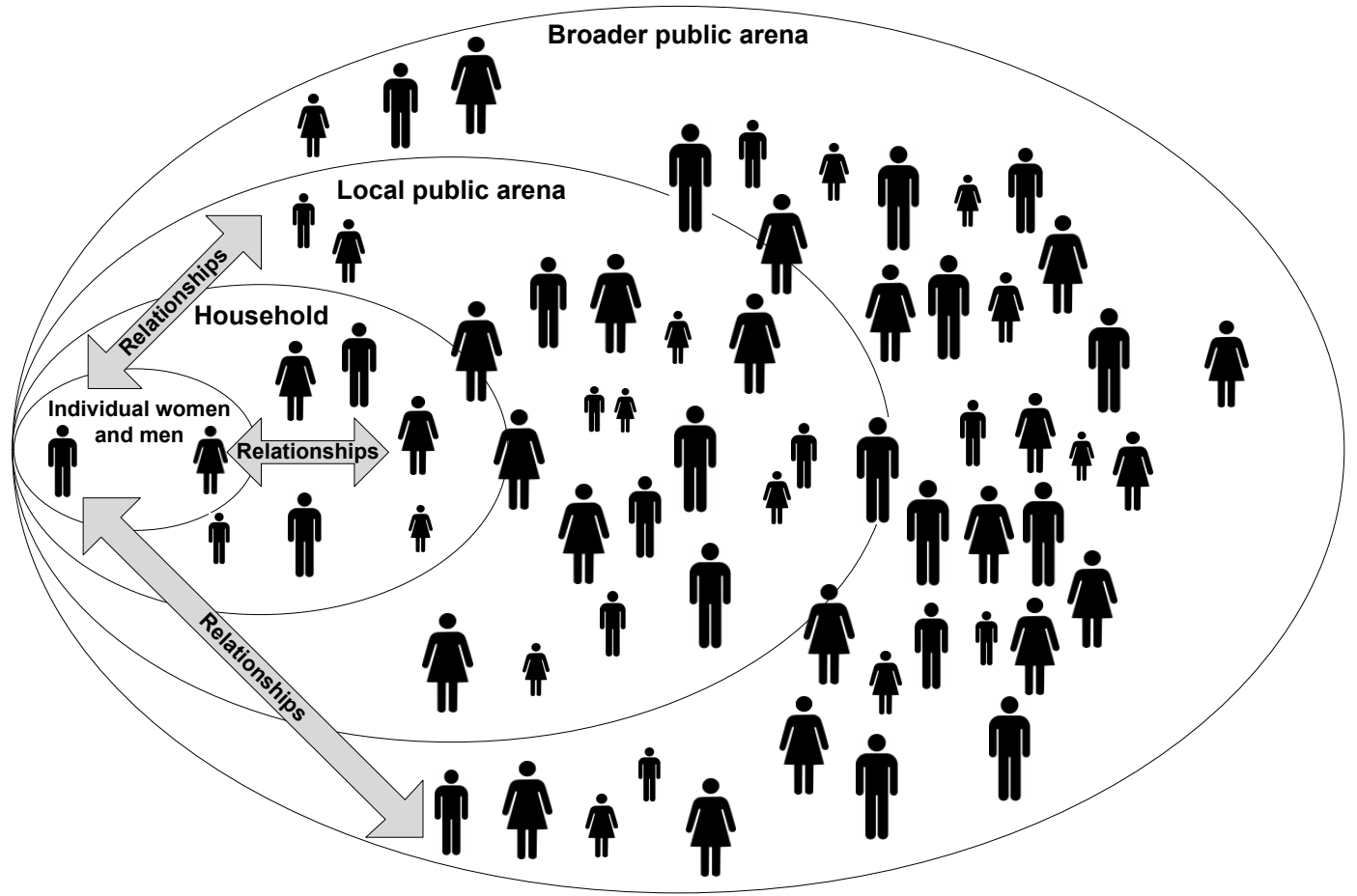

Figure 2 The framework as nested and interconnected spaces through which roles and relationships shape and are shaped by gender

It is helpful to consider the relevance of scale with reference to analytical approaches taken in gender equality literature, to explain why scale was selected as a useful way to classify changes in gender roles and relationships. First, the four key institutions of family, community, market and state 
proposed in the social relations approach to gender analysis (Kabeer, 1994) can be located within and across the scales proposed. The family level is dominantly conceived at the household and local public scales, while community, state and market dynamics can play out across all levels from household to local and broader public arenas. Viewing the different outcomes related to these institutions across scales may help us to consider the relative contribution of development initiatives to social change, including whether their reach has been primarily local or whether changes in the broader arena or 'enabling environment' for gender equality can also be observed.

Second, a scalar approach to analysis can encompass both practical outcomes (e.g. direct benefits from access to water) and strategic gender interests (e.g. shifts in power and status) (after Moser, 1993), with both practical and strategic outcomes relevant across household and public spheres. Different questions arise when considering what might constitute practical and strategic interests within households, compared with at the community level and more broadly, meaning an approach to inquiry that looks across these scales may offer insights into strategic gender interests that might not otherwise be considered within a WASH program. This includes questions around access to and control over resources (a key area of analysis within the Moser framework), as well as how women and men manage their various roles.

The proposed framework also provides spaces for inquiry into dimensions of women's empowerment which comprise individual, household and community changes relating to formal and informal structures, institutions and norms, power, agency and control over resources (including financial resources) and assets (for example see CARE, 2010; Golla et al., 2011; Oxfam, 2009). As such it does not seek to supplant existing frameworks, but to encompass key components in a form tailored for the WASH sector and spanning the experiences of both women and men.

Finally, recognising that scale is socially constructed and relational and acknowledging the interdependencies of social processes across different levels, scale can nevertheless be (loosely) bounded with reference to physical locations and spaces. In seeking to increase the accessibility of gender equality concepts for WASH practitioners so they are empowered to make gender equality a meaningful focus of their work, it is helpful to think in terms of physically bounded (if blurred) spaces for analysis. In contrast to often abstract institutional frames of analysis around states and markets, it is hoped that inquiry across defined scales may be more relevant for those involved in WASH initiatives who are influencing and evaluating gender equality changes where they work.

As such, the three scales included in the framework reflect the levels at which WASH initiatives typically seek to create change, and have most capacity to influence. They also reflect that analysis and reported gender equality outcomes to date have focused on the household and local community scales, so these are key areas for inquiry. But they extend the focus of interest to consider changes in the broader public arena, which shapes the enabling environment critical for sustainable WASH service delivery. This is the level at which leading WASH programs are increasingly aiming to focus (Willetts et al., 2012).

Each of the spaces is now described in turn, providing examples of gender equality outcomes reported in WASH literature and empirical research. Where outcomes transcend a specific scale or cannot be easily located within one 'area of change' they are discussed in the most appropriate place, or sometimes in two areas where changes are particularly common or significant. 


\section{Individual changes within the household sphere}

Reflecting the tendency for gender-focused WASH initiatives and related literature to focus on gendered roles in household tasks, the largest number of outcomes identified in the literature review (approximately one third of all outcomes) were situated within this space. Themes include practical outcomes stemming from improved WASH facilities and services, such as a reduction in women's labour, as well as potentially more strategic interests (as described by Moser 1993) including increased self-confidence for women and men, and changing attitudes about traditional domestic roles. Examples of the former typically focus on women's use of time, finding that accessing water close to the home and/or improving sanitation and hygiene reduces the burden of labour related to carrying water and caring for sick family members (for example see Willetts et al., 2010; Fisher, 2010; NEWAH, 2004; Kilsby, 2012). It is important to note that while the literature and recent empirical research supports the commonly held view that improving WASH reduces particular forms of labour, it cannot be assumed that women's overall burden of work necessarily reduces (Ivens, 2008) or that an increase in available time translates to greater participation in off-farm work for rural women (Koolwal and van de Walle, 2010). Care is therefore needed when reporting outcomes, as commonly held assumptions about the impact of increased time are not always supported by evidence.

Moving beyond practical outcomes, a number of studies discuss shifting attitudes around traditional gender roles, as well as changes in self-perceptions. These range from enhanced privacy and dignity resulting from improved sanitation and more easily managed hygiene (e.g. Fisher, 2010; Ivens, 2008) to increased self-confidence for women. For example in a review of gendered WASH outcomes collated for the Water Supply and Sanitation Collaborating Council, Fisher (2010) links improved hygiene to increased self-confidence: "when the women in Songambele village, Tanzania, were able to bathe regularly during menstruation, they reported that their improved personal hygiene resulted in increased confidence".

A change in the attitudes of men in program areas is also noted. For example in a review of a Gender and Poverty approach to WASH in Nepal, Pandey (2003) profiles a male community worker who reported that "a positive change in attitude" had resulted from gender awareness training, challenging a traditional belief that "only women carry out jobs like cooking and cleaning" and facilitating increasing male participation in community health activities. Similarly, and moving from a change in attitude to a change in practice, Rop (2010) reports that a Senegalese program aiming to involve men in handwashing behaviour change resulted in men playing a more active role in hygiene behaviour as role models, encouraging their families to adopt handwashing practices.

While most of the outcomes reported at the intersection of individual/household scales are framed as positive for gender equality and women's empowerment, one study cites mixed and negative impacts associated with a sanitation program. In analysis of a sanitation program in Rajasthan, O'Reilly (2010) describes the ways in which a sanitation marketing program resulted in reduced mobility and increased seclusion for women. It was assumed that a participatory project approach would empower women and help to counter social norms linking wealth and status to household seclusion, with poorer or lower caste women more often outside the home (van Wijk-Sijbesma, 1998 cited in O'Reilly, 2010). Instead, as O'Reilly (2010) writes, “household latrines created reasons for women to remain in seclusion at home...[so] latrines play a role in simultaneously subverting and reinforcing gendered social norms regarding women's mobility inside and outside their homes". 
Given gender inequality exists at multiple levels and in multiple spaces, and that specific gender norms will operate in those different spaces, gains for women in one area (meeting practical needs associated with sanitation, enhanced dignity) may not translate into benefits elsewhere - and indeed, may create opportunities for greater conformity with the gendered norms operating in other spaces.

\section{Changes in relationships within the household sphere}

We move now to relationships between women and men and within gender groups, beginning first with relationships that mediate gender equality within the household sphere. Overall, fewer outcomes related to relationships in the private sphere were reported compared with those focused on gendered roles, and none dealt with relationships within gender groups. The absence of literature on private sphere relationships is likely due to the hesitancy to focus on 'domestic' spaces and relationships outside of areas where the relationship itself is necessarily a primary focus, such as 'domestic' violence, family planning and HIV/AIDS programs.

Nevertheless, some significant findings have been reported, particularly arising from recent empirical research undertaken in Fiji, Vanuatu and Timor Leste. For example in Timor-Leste, Kilsby, (2012) found:

The benefits most frequently mentioned by women are improvements in family harmony. This is rarely if ever an outcome that WASH programs deliberately set out to achieve or to measure, yet for the women in the two research communities, this is the most significant change the program has brought to their lives.

Similarly, research with communities in Fiji and Vanuatu found outcomes including improved communication between husbands and wives, increased respect given to women by men in their households and women feeling more valued, and in one community a reduction in gender-based violence. In one example from Fiji, improved relationships resulting from reduced friction over water enabled a renegotiation of household roles, as described by a female participant: "the women then negotiated at the household level that the men should carry the water also - they share the labour now" (Willetts et al. 2009a). A male leader in Vanuatu spoke about the impact of improved access to water on his relationship with his wife (Willetts et al. 2009b):

"Then my wife used to tell me to get some water. I would say it's too much work and I would get angry, we would fight and I would hit her...Since the water has come the kids are healthy, there's less work, I can spend more time in the garden and there's no more fighting with my wife."

This finding of a reduction in incidents of violence directly linked to reducing conflict over managing workloads associated with water provision is important. However, it does not necessarily indicate a change in underlying attitudes towards the use of violence against women and thus in the long-term risk of violence. A current trigger has been removed, but if attitudes accepting of violence and gender inequality more generally remain unchallenged, the life-time risk of violence for women may be little affected.

In contrast to these examples, Ivens (2008) describes a program in Benin where access to water supply resulted in improvements to women's quality of life, but did not serve to address power imbalances within households or to enhance women's negotiating power.

...women's participation did not contribute to enhanced negotiation power in the household. As a result, women's workload did not decrease. Nor were women able to use the time gained for preferred activities. 
Instead of taking up activities that would have increased their economic independence, they used the extra time gained to work in their husbands' fields, as per their husbands' preference.

This reflects the tendency for WASH programs to focus on individual gender roles and responsibilities in the household sphere, rather than addressing the potentially more challenging questions of power and status played out through relationships. It also illustrates that given gender inequality operates at multiple levels and is embedded deep in social, economic and cultural structures and practices, quality of life changes associated with WASH improvements do not necessarily translate into more strategic gender equality outcomes, as is sometimes assumed.

\section{Individual changes within the local public arena}

Changes in the local public sphere are those most commonly sought in community WASH initiatives, through efforts to ensure the participation of women and address gender equality in and through the governance of WASH related infrastructure and services (for example the representation of women on community WASH committees). Reflecting this, commonly reported outcomes in this sphere relate to education and to the increased participation of women in community decision making forums.

Improved educational opportunities for girls are cited as amongst the most important and valued benefits from WASH programs for gender equality and poverty reduction more broadly. Benefits result from increased access to both water and sanitation and related health benefits (primarily through reduced sick days). The theory of change suggests that when water is readily available, girls are free to attend school in time previously spent on household chores such as water collection, which is typically the primary responsibility of women and children (WHO/UNICEF, 2010). This is supported empirically (e.g. Koolwal and van de Walle, 2010; Brewster et al., 2006) with research finding substantial increases in school enrolment rates and attendance.

For sanitation, when girls have access to safe, adequate facilities at school-particularly during menstruation - attendance rates increase and girls stay in school for longer. There are numerous project and program examples of increased school attendance resulting from provision of appropriate sanitation facilities. An example from Tajikistan is described by Fisher (2010): "An assessment of 20 schools in rural Tajikistan revealed that all girls chose not to attend during their menstruation as there were no sanitation facilities available. Where these are provided, school enrolment increases and drop-out rates decrease." Similarly, Brewster et al. (2006) describe a number of programs and examples, including a school sanitation project in Bangladesh with separate facilities for boys and girls that resulted in an average annual increase in girls' school attendance of 11\% from 1992 to 1999.

For females beyond school age, empirical research in the Pacific found that women were taking on non-traditional roles in and through their participation in WASH activities (Willetts et al. 2009b). One woman in Vanuatu shared her experience gaining skills in infrastructure construction:

\footnotetext{
...I didn't know how to construct all of these slabs. But with the male staff we work as a team. I've learnt how to do all of these things - seat raisers, tap stands, soakaways. I had no idea, so it's a big change. I can do it by myself and help my own community. I don't need to wait for the male staff. When they aren't there I can do it by myself.
} 
Also in Vanuatu, women discussed that through WASH initiatives, they were taking on leadership roles for the first time in their community.

"... now we have representation on the committee... Before women didn't talk in community meetings, now they participate and also take decisions. It makes me so proud that we have a voice in development compared to previous years where only men talked"

Increasing participation in community forums resulted from, and further enhanced, self-confidence for women. Similarly, from individual empowerment, Fisher (2010) in her synthesis of WASH-related gender outcomes, reports women gaining self-confidence, becoming positive role models and beginning to occupy public and influential roles.

Research in Timor Leste found comparable outcomes, including women becoming positive role models through their participation in WASH activities and demanding greater recognition for their contribution to community life. As one male participant observed: "women can be good role models or good examples for other women to contribute to this country". This corresponded with acknowledgement of women's rights by both women and men, with the research itself contributing to increased awareness: "now males know and understand about women's rights, before the research there was no information about this".

This finding reflects that outcomes for women at the community scale - including increasing awareness of women's rights and the extent to which they voice their expectations and demands depend on shifts in the attitudes of men, which are in turn gender equality outcomes in and of themselves. Research in Fiji and Vanuatu found that the attitudes of men towards women's roles and status had changed, with men more accepting of women's contribution to community decision making. As one Fijian village headman shared:

We like the roles women play and we acknowledge them. It doesn't disturb the traditional leadership as it's our responsibility as men to listen to our women. For us not to would be unfair. We see that things are changing slowly, in the past we didn't listen so much. We see it as positive and appreciate it. We see that things are changing and that the women put their views forward and it is not done in a challenging way, it's seen as supportive and an improvement.

These outcomes are significant for individuals in that they reflect a transformation in attitude. They are also a critical driver of gender relationships across both household and public arenas, with attitudinal changes at the personal scale a pre-requisite for meaningful and lasting changes in power and status between men and women, as discussed below.

\section{Changes in relationships within the local public arena}

Relationships that shape gender equality within the local public arena include social networks as well as institutions such as community governance committees and/or WASH user groups. Women's role in local governance has emerged as a theme in WASH programming in recent years, particularly with reference to community-managed systems in rural areas. Within many WASH initiatives promoting the representation of women on WASH committees (often with a nominal quota) serves as a program objective and indicator of the extent to which an activity has engaged with and advanced gender equality.

Inclusive approaches to WASH that explicitly foster the participation of women can influence the ways women and men interact in community life. This includes creating space for women to be a 
part of and influence decision making, building from individual changes (increasing self-confidence, shifts in attitudes) to changes in relationships. An example from Fiji (Willetts et al., 2009a) illustrates how a collaborative WASH program was linked to changes in respect, which in turn led to shifts in women's power and influence in community decision making. As one man described:

There has been more collaboration amongst people, men and women talk properly together and listen. Men are able to listen to the women more compared to the past... The norm is in a village meeting the men / leaders would speak and tell people what to do - it was one way communication and decision making. The [project] helped us to listen together and we started to value the discussion and sharing of ideas before arriving at a decision.

A woman commented on the significance of this shift in the community, as "before the projects, when women raised views in community meetings they weren't taken seriously". Having worked together through the WASH project, according to one man, "men are able to listen to the women more compared to the past". This sentiment was echoed by a female participant:

The response to women has changed, they are more listened to, there is more trust of women... Women have gained respect.

Similar stories are reported from Vanuatu (Willetts et al., 2009b) and Nepal (James et al., 2004), where women taking on responsible positions in project management committees was reported to lead to more active participation in community meetings. However it is important to note that an increase in participation does not necessarily reflect a deeper shift in power and therefore in gender equality. Reported gender outcomes reflect a spectrum of levels of participation, from women being present at relevant meetings through to women expressing views, being listened to and influencing decision-making. In assessing gender equality outcomes, it is critical to interrogate what 'participation' actually means (and which women and men within a community participate) to determine whether meaningful changes in status and power have occurred, or whether participation has been of a more token kind.

Research with communities in Timor-Leste (Kilsby, 2012) illustrated the complexity of participation as a gender equality outcome, and the mediating role of relationships across both public and household spheres. When discussing and ranking changes resulting from participation in a WASH program, women and men identified increasing opportunity for women to participate in community meetings and contribute to decision-making as significant community-level changes. However inequities in participation were found, with only some women feeling able to take advantage of the opportunity of increasing space for women's voices. One woman identified that household responsibilities including child care were preventing her from attending meetings: "Men don't stop us from coming to meetings, we just have too much to do. We have to wait for husband to come and take the kids, we couldn't come until he does that". This indicates, as Kilsby (2012) notes, that "even where women do not feel constrained by men's attitudes to their participation in community life, they are still in a practical sense dependent on men's support to enable them to take up the opportunity". As such, gender relations at the household scale in this instance diluted opportunities for meaningfully shifting relationships at the community scale.

\section{Changes in individuals and relationships within the broader public arena}

The broader public arena encompasses spaces beyond social and community networks including national and sub-national government institutions as well as medium to large private sector and civil society organisations. We include the broader public arena as an area for consideration in 
recognition of the significance of this scale in shaping the enabling environment for WASH, despite a paucity of reported outcomes at this level. Literature on possible approaches for working at this level exist (for both public and private sectors), however only a few elucidate what kinds of outcomes these approaches can lead to. Yet both individual and relationship changes are highly relevant at these scales, as the personal plays out in and through institutions just as it does in family and community networks, reflecting and influencing societal norms regarding gender equality.

So with a view to informing further investigation of WASH-related gender outcomes in the broader public arena, we have identified areas of possible change at this scale, building on our collective experience across the WASH and gender and development sectors. These are summarised in the synthesis framework below. Anticipated outcomes at this scale span public, private and nongovernment sectors, and include changes relating to the employment of women in WASH sector institutions and technical roles, shifts in the dynamic between women and men (increasing trust of and respect for women playing leadership roles at this scale) and changes in the extent to which women are able to actively voice their rights and preferences at higher levels of government. Outcomes might also relate to policies, laws and investments, for example changes in WASH investments relevant to advancing gender equality, and changes in national, regional or international commitments that recognise and endorse gender-responsive approaches to WASH.

The few examples of these kinds of outcomes reported in the literature include a case in Peru, where enactment of a law promoting equal opportunities for women and mean led to changes in local government approaches to service delivery and consequent reforms within small town water suppliers whereby women and men were given equal representation on management oversight boards (Zevallos, 2007 cited in Rop 2010). Another case relates to women's employment within the national ministry responsible for water management in Uganda. Following an agency review and development of a Water Sector Gender Strategy, a Water Liaison Division was established and efforts were made to appoint staff with sociology and gender mainstreaming skills to work across the organisation. From a situation with no women in management and a staff consisting entirely of people with infrastructure development skills, the Ministry now has $18 \%$ representation of women in managerial roles and a diversified skills base better equipped to address gender issues (Rop, 2012).

\section{Synthesis}

Building on analysis of outcomes described above, this section provides a synthesis of typical and anticipated gender outcome areas associated with WASH programs arranged within the framework (Figure 3). It then reflects on the process of developing the framework and identifies potential applications as well as aspects that would benefit from further empirical investigation. 


\begin{tabular}{|c|c|c|c|}
\hline & \multirow{2}{*}{$\begin{array}{l}\text { Household sphere } \\
\text { Household and family networks }\end{array}$} & \multicolumn{2}{|c|}{ Public arena } \\
\hline & & $\begin{array}{l}\text { Local public arena } \\
\text { Social and community networks }\end{array}$ & $\begin{array}{l}\text { Broader public arena } \\
\text { Governance institutions and beyond }\end{array}$ \\
\hline $\begin{array}{l}\text { Changes in self/ } \\
\text { individuals } \\
\text { Includes changes for } \\
\text { women or men } \\
\text { Includes changes } \\
\text { relating to roles as well } \\
\text { as self-perception and } \\
\text { attitudes }\end{array}$ & $\begin{array}{l}\text { Changes in access and usage of water, sanitation and } \\
\text { hygiene services } \\
\text { Changes in attitudes about gendered household roles and } \\
\text { responsibilities } \\
\text { Changes in the distribution of household roles and labour } \\
\text { between women and men } \\
\text { Changes in total hours worked, taking into account paid } \\
\text { and unpaid work } \\
\text { Changes in discretionary time } \\
\text { Changes in self-confidence, particularly for women } \\
\text { Changes in self-awareness around gender roles and } \\
\text { relationships including possibilities, opportunities and } \\
\text { negotiating power } \\
\text { Changes in levels of mobility and/or seclusion for women } \\
\text { Outcomes relating to increasing and/or diversifying income } \\
\text { opportunities and skills for women and men }\end{array}$ & $\begin{array}{l}\text { Changes in self-confidence, particularly for women } \\
\text { Educational outcomes, relating to girls' education and literacy } \\
\text { Change in awareness of women's rights by men and women } \\
\text { Changes in the number of women occupying public and } \\
\text { potentially influential roles in their community } \\
\text { Changes in the extent to which women are voicing their } \\
\text { expectations and demands relating to community governance } \\
\text { Changes in levels of mobility and/or seclusion for women } \\
\text { Changes in personal safety for women } \\
\text { Outcomes relating to increasing and/or diversifying income } \\
\text { opportunities and skills for women and men, including } \\
\text { opportunity to take up non-traditional roles }\end{array}$ & $\begin{array}{l}\text { Changes in the number of women occupying potentially influential roles } \\
\text { in government and private sector institutions } \\
\text { Changes in the number of women occupying technical roles in government } \\
\text { and private sector institutions } \\
\text { Changes in the extent to which women are voicing their expectations and } \\
\text { exerting influence within higher levels of government (e.g. provincial, } \\
\text { national) } \\
\text { Changes in women's leadership on WASH issues at larger scale (beyond } \\
\text { their local community) }\end{array}$ \\
\hline $\begin{array}{l}\text { Changes in } \\
\text { relationships } \\
\text { Includes changes in } \\
\text { relationships between } \\
\text { women/men and within } \\
\text { gender groups }\end{array}$ & $\begin{array}{l}\text { Changes in negotiating power in household relationships } \\
\text { Changes in financial status and power including control } \\
\text { over household resources and assets } \\
\text { Changes in communication between husbands and wives } \\
\text { Changes in the ways decisions are made, including who is } \\
\text { involved and consulted } \\
\text { Changes in levels of respect between men and women in } \\
\text { the household } \\
\text { Changes in levels of conflict and harmony (including } \\
\text { gender-based violence) within households }\end{array}$ & $\begin{array}{l}\text { Changes in the status of women in the community life } \\
\text { Changes in the level of trust and respect afforded to women in } \\
\text { the community } \\
\text { Changes in the ways in which women and men cooperate and } \\
\text { work together in the community } \\
\text { Changes in solidarity within and between gender groups } \\
\text { Shifting of traditional social norms, including the diversity of } \\
\text { roles available for women at the community level } \\
\text { Shifting of restrictive/harmful social attitudes/ practices/ } \\
\text { exclusion/ taboos associated with menstruation and child birth } \\
\text { Changes in the extent to which women's perspectives are } \\
\text { listened to and inform decision making at the community level } \\
\text { Change in recognition of women's rights by men and women } \\
\text { Outcomes relating to women and men becoming positive } \\
\text { gender role models in their community }\end{array}$ & $\begin{array}{l}\text { Changes in the status of women in public life } \\
\text { Shifting of traditional social norms, including the diversity of roles } \\
\text { available and acceptable for women in the public and private sectors } \\
\text { Changes in the level of trust and respect afforded to women in influential } \\
\text { and technical roles in government and private sector institutions } \\
\text { Changes in policies and programs that support equal participation of } \\
\text { women and men in influential and/or technical roles in government and } \\
\text { private sector institutions } \\
\text { Outcomes relating to women and men becoming positive gender role } \\
\text { models in their district, province or nation } \\
\text { Changes in priority given to WASH investments relevant to advancing } \\
\text { gender equality, as reflected in budget allocations at this scale } \\
\text { Changes in media and public debate about WASH investments and gender } \\
\text { equality } \\
\text { Changes in the representation of female and male water users on } \\
\text { consultative bodies, advisory groups and boards established by water } \\
\text { utilities } \\
\text { Changes in national, regional or international WASH commitments } \\
\text { relevant to gender equality (e.g. recognition of the right to sanitation, } \\
\text { policy commitments about provisioning for separate facilities for girls in } \\
\text { school) }\end{array}$ \\
\hline
\end{tabular}


In interpreting this summary, it is important to note its scope and limitations to inform potential application. First, the outcome types should not be considered comprehensive of all possible gender changes that can be achieved by WASH programs. Most of the available literature is focused on rural areas and on household and local community scales. Questions remain about applicability of reported outcomes to urban areas, and to local, provincial and national governance scales (Ivens, 2008). There is also a gap in evidence around gender outcomes at different stages of life (the relevance of which is discussed in Tsukada and Silva, 2009; Mazurana et al., 2011), with adolescent and younger girls receiving limited attention with reference to menstrual hygiene and school attendance. Similarly, outcomes for older women and pregnant women are largely absent from the literature and there is limited discussion focused on female-headed households as a specific and critical group. Across all of these areas, most reported outcomes relate to women and there is a gap in exploration of changes experienced by men and boys. There is also little consideration of other potential layers of discrimination and inequality such as socio-economic status, disability and ethnicity. Further work is needed to consider these areas, and the framework would need to be extended in light of emerging additional evidence.

More broadly, across the available literature there is a tendency to report on the kinds or types of gender equality outcomes that can be achieved in an aspirational sense, with only a subset providing rigorous evidence and examples of achievements. There is an acknowledged need in the literature for further empirical research to explore the purported benefits of WASH initiatives for gender equality, to establish what actually occurs in different contexts and across different programmatic approaches (for example Koolwal and van de Walle, 2010; Ray, 2007).

Second, outcomes are expressed in neutral language as "changes" to ensure both positive and negative changes for gender equality can be captured. While most of the outcomes reported in literature and summarised here are positive, the influence of selection bias is potentially significant (as discussed by Ray, 2007), and the possibility that WASH programs can entrench or exacerbate gender inequities needs to be acknowledged and monitored. When planning or monitoring gender outcomes, it is therefore important to be explicit about the intended or preferred direction of change, and to describe outcomes with reference to locally determined notions of positive gender equality. As such, it is intended that the framework offers space for diversity in definitions and interpretations of what gender equality means in different contexts and for different groups, while providing a structured approach for engaging with the often challenging and culturally-based issues of power and status.

Third, the question of causality remains unresolved in this framework, which does not offer a theory of change but rather a means by which to engage with changes occurring in locations where WASH initiatives have been undertaken (or are planned). It is problematic in any social assessment to isolate the impacts of one particular development intervention, as social outcomes are by definition mediated by a range of complex and interrelated factors. Our aim is not to present a model of change, but a structure for engaging with gender outcomes, which can inform the development and refinement of WASH approaches that have most potential to achieve positive gender equality outcomes.

Reflecting on identified WASH-related gender outcomes and the process of developing the framework, the author team (comprising a mix of WASH and gender specialists) discussed similarities and differences between the proposed framework and others used by practitioners within gender equality and women's empowerment fields (for example CARE, 2010; CARE, 2012; Golla et al., 2011; Hunt et al., 2009). While our particular groupings are distinct, the underlying gender equality concepts are established and widely used 
within the development sector. This led us to question whether the proposed framework was sufficiently novel to warrant presentation, and whether there is value in contributing another frame in a sector crowded with conceptual and methodological tools. Ultimately, we concluded that 'newness' in conceptual terms was not essential for the framework to make a contribution. Our aim is to share a tool tailored for WASH practitioners in order to de-mystify gender equality outcomes (encompassing and going beyond the practical outcomes associated with increased access), and make clearer the links between WASH and gender. We hope that the clarity of a matrix-style framework and the synthesis of real examples within each space will be useful for practitioners seeking to strengthen the contribution of their WASH work to achieving positive gender equality outcomes.

The framework has been used by the authors as a tool to guide thinking during a WASH program evaluation in Timor-Leste, and when working with WASH practitioners in Vanuatu. Preliminary feedback suggests that the tool may be particularly helpful for practitioners seeking to engage with the complexity of gender equality. It provides a structure through which teams can discuss and deliberate about gender equality, and the influence and impact of their work. It is accessible for non-specialists, while also (through its grounding in both theory and practice) avoiding over-simplification of gender equality concepts.

\section{Conclusion}

Explicitly integrating gender equality in WASH programs has been shown to enhance effectiveness and sustainability. There is also significant potential for WASH programs to contribute to gender equality more broadly, given women's traditional roles in WASH and the certainty that all development interventions have different outcomes for women, men and relationships. The synthesising framework proposed in this paper offers a structure for engaging with a broad set of gender equality outcomes relevant to WASH. It integrates critical areas of inquiry related to roles, relationships, status and power, and spans the various scales at which these play out, from household to community and beyond. Building on the review and synthesis of outcomes presented here, it is hoped that the framework can be applied and refined by practitioners, policymakers, development programmers and researchers, strengthening the evidence base on the ways in which WASH can influence and advance gender equality. There is also need to consider the gender impacts of programs over the long-term, investigating whether (and how) WASH initiatives have a lasting impact on gender equality. It is hoped that the proposed framework offers a structure for exploration of these questions, contributing to sector knowledge on WASH-gender links and facilitating inquiry that moves beyond 'practical access' outcomes towards more profound and challenging gender equality questions relating to status and power.

\section{Acknowledgements}

The research presented in this paper was supported by AusAID through the Australian Development Research Awards grants program. The research was led by the Institute for Sustainable Futures, University of Technology, Sydney in partnership with the International Women's Development Agency. The authors would like to acknowledge the contributions of participating communities in Fiji and Vanuatu as well as staff and facilitation teams from Live and Learn Fiji and World Vision Vanuatu. 


\section{References}

Brenner, N. (2001) 'The limits to scale? Methodological reflections on scalar structuration', Progress in Human Geography, 25 (4): 591-614.

Brewster, M. M., Herrmann, T. M., Bleisch, B. and Pearl, R. (2006) 'A Gender Perspective on Water Resources and Sanitation', Wagadu, 3.

CARE (2012) Good Practices Framework: Gender Analysis, CARE International Gender Network, May 2012.

CARE (2010) Strong Women, Strong Communities: CARE's holistic approach to empowering women and girls in the fight against poverty, CARE Australia, July 2010.

Fisher, J. (2010) 'Women in water supply, sanitation and hygiene programmes', Municipal Engineer, 161 (ME4): 223-229.

Golla, A. M., Malhotra, A. Nanda, P. and Mehra, R. (2011) Understanding and Measuring Women's Economic Empowerment: Definition, Framework and Indicators, International Center for Research on Women (ICRW).

Halcrow, G., Rowland, C. Willetts, J., Crawford, J, and Carrard, N. (2010) Resource Guide: Working effectively with women and men in water, sanitation and hygiene programs, International Women's Development Agency and Institute for Sustainable Futures, University of Technology, .

Hunt, J., Kasynathan, N., Yogasingham, S., Fernando, D., Gamage, P. and Roubin, D. (2009) Breaking the shackles: Women's empowerment in Oxfam Australia's Sri Lanka program, Occasional Paper Number 3, Oxfam Australia, Melbourne.

Ivens, S. (2008) ‘Does Increased Water Access Empower Women?’, Development, 51, pp63-67.

James, A. J., Khadka, R., Moffatt, M. and Otte, C. (2004) 'From MPA to NPA: participatory assessment of water \& sanitation projects in rural Nepal', Participatory Learning and Action, 50: 190-194.

Koolwal, G. and van de Walle, D. (2010) Access to Water, Women's Work and Child Outcomes, Policy Research Working Paper 5302, World Bank Poverty Reduction and Economic Management Network, Gender and Development Unit.

Kabeer, N. (1994) Reversed Realities: Gender Hierarchies in Development Thought, Verso, London.

Kilsby, D. (2012) 'Now we feel like respected adults': Positive change in gender roles and relations in a TimorLeste WASH program, research conducted by International Women's Development Agency, WaterAid Australia and WaterAid Timor-Leste.

Lockwood, H. and Smits, S. (2011) Supporting rural water supply; moving towards a service delivery approach, Practical Action and IRC International Water and Sanitation Centre.

Marston, S. A. and Smith, N. (2001) 'States, scales and households: limits to scale thinking? A response to Brenner', Progress in Human Geography, 25 (4): 615-619.

Marston, S. A. (2000) 'The social construction of scale', Progress in Human Geography, 24 (2): 219-242. 
Mazurana, D., Benelli, P., Gupta, H. and Walker, P. (2011) Sex and Age Matter: Improving Humanitarian Response in Emergencies, Feinstein International Center, Tufts University.

Moser, C.O.N. (1993) Gender Planning and Development: theory, practice \& training, Routledge, London and New York.

NEWAH (2004) A Summary of Evaluation Findings of NEWAH's GAP Approach Using the NEWAH Participatory Assessment (NPA), Nepal Water for Health, Kathmandu.

O’Reilly, K. (2010) 'Combining sanitation and women's participation in water supply: an example from Rajasthan', Development in Practice, 20(1): $45-56$.

Oxfam (2009) Breaking the shackles: Women's empowerment in Oxfam Australia's Sri Lank program.

Pandey, U. (2003) 'Strategies for serving the poorest of the poor with sanitation - a gender and poverty approach', paper presented at the South Asian Conference on Sanitation, Dhaka, 2003.

Ray, I. (2007) 'Women, Water, and Development', Annual Review of Environment and Resources, 32(1): 421449.

Rop, R. (2010) Mainstreaming Gender in Water and Sanitation Gender in Water and Sanitation, World Bank Water and Sanitation Program Working Paper.

Tsukada, R and Silva, E. 2009. 'Age and gender bias in workloads during the lifecycle: Evidence from rural Ghana', International Policy Centre for Inclusive Growth One Pager, No.88,

WHO/UNICEF Joint Monitoring Programme (JMP) for Water Supply and Sanitation (2010) Progress on Sanitation and Drinking-Water, 2010 Update.

Willetts, J., Halcrow, G., Carrard, N., Rowland, C. and Crawford, J. (2010) 'Addressing two critical MDGs together: gender in water, sanitation and hygiene initiatives', Pacific Economic Bulletin 25(1): 162.

Willetts, J., Bailey, B. and Crawford, P. (2012) Civil Society Water, Sanitation \& Hygiene Fund Independent Completion Review, report for AusAID, available at http://www.ausaid.gov.au/aidissues/watersanitation/Documents/wash-completion-review.pdf.

Willetts, J., Carrard, N., Halcrow, G., Rowland, C. and Crawford, J. (2009a) How do we better address gender in Pacific water and sanitation initiatives? Fiji Case Study, http://genderinpacificwash.info.

Willetts, J., Halcrow, G. and Carrard, N. (2009b) How do we better address gender in Pacific water and sanitation initiatives? Vanuatu Case Study, http://genderinpacificwash.info. 


\section{Author information}

Naomi Carrard (corresponding author)

Institute for Sustainable Futures - University of Technology, Sydney

Naomi Carrard is a Research Principal at the Institute for Sustainable Futures, an independent research and consulting centre within the University of Technology, Sydney. Naomi's expertise is in water, sanitation and hygiene (WASH), gender equality and the role of civil society in development. She has a background in Geography and Environmental Law and works with government, industry and civil society informing policy and practice towards effective and sustainable development.

\section{Joanne Crawford}

International Women's Development Agency and Australian National University

Joanne Crawford leads IWDA's research and policy engagement, and currently holds a joint appointment as ANU Research Associate on an international collaboration developing a new gender-sensitive poverty measure. She has $25+$ years' experience working with government, civil society and bilateral and multilateral agencies, focused on gender equality, development and public policy.

\section{Gabrielle Halcrow}

\section{SNV Asia}

Gabrielle Halcrow is a water, sanitation and hygiene specialist (WASH) with SNV Asia. She has a technical background in international health and environmental management with 12 years international development experience working with WASH, gender equality and public health programs with both governments and international organizations in Asia and the Pacific.

\section{Claire Rowland}

Independent consultant

Claire Rowland is a consultant with nine years' experience in the international development sector. She has a broad range of gender analysis and programming skills, and specializes in development research and program evaluation, particularly in relation to WASH, economic development, peace building and women's empowerment programs.

\section{Associate Professor Juliet Willetts}

Institute for Sustainable Futures - University of Technology, Sydney

Dr Juliet Willetts is a development researcher leading innovative research, consultancy and evaluation for bilateral, multilateral and non-governmental agencies to influence policy and practice. She engages in issues of gender equality, civil society role in development, water, sanitation and hygiene, climate change and development effectiveness more broadly. 